\title{
Noción de "espíritu" en Karl Rahner: una perspectiva de filosofía de la religión ${ }^{1}$
}

\author{
Fernando Berríos \\ FACULTAD DE TEOLOGÍA \\ PONTIFICIA UNIVERSIDAD CATÓLICA DE CHILE \\ fberriosm@uc.cl
}

Resumen: "Espíritu" es para Karl Rahner una noción ante todo antropológica, pero en una concepción del ser humano no cerrada, sino abierta a la trascendencia. Releyendo Hörer des Wortes, se estudia aquí esta noción en perspectiva de una filosofía de la religión (1) y vinculada al concepto de "anticipación" (Vorgriff), en el horizonte del ser absoluto que "se oculta" (2). Luego se analiza la condición "espiritual" en el plano de la libertad del hombre como "oyente" de una posible revelación (3) y finalmente se considera el "lugar" concreto en que para Rahner acontece este evento: el mundo material e histórico (4).

Palabras clave: Espíritu, Filosofía de la religión, Anticipación.

Abstract: For Karl Rahner, the concept "spirit" is, in the first place, an anthropological notion; nevertheless, not one limited to a closed conception of man but open to transcendence. In this paper the concept "spirit" in Hörer des Wortes is first considered from the point of view of the Philosophy of religion(1) and linked to the concept "anticipation" (Vorgriff), in the realm of the "hidden" absolute being(2). Then follows an analysis of the human condition as "spiritual" in the context of man's freedom as "listener" of God's potential revelation(3). Finally, the article deals with the "place" where, according to Rahner, this event takes place: the material and historical world.

Keywords: Spirit, Philosophy of Religious, Anticipation.

1 El presente trabajo es fruto del proyecto de investigación Fondecyt Regular $\mathrm{N}^{\circ}$ 1130019 (2013-2014), sobre el tema general: "El espíritu humano y la dramaticidad de su trascendencia en Edith, Stein, Anselmo, Juan de la Cruz y Karl Rahner”. 


\section{INTRODUCCIÓN}

"Espíritu" es en la obra de Karl Rahner ante todo una noción antropológica ${ }^{2}$. La desarrolló primeramente en su obra Geist in Welt, Espiritu en el mundo (en adelante $G W$ ), que fue en su origen una tesis doctoral en filosofía concluida en 1936 en la Universidad de Freiburg, Alemania, pero que nunca llegó a ser formalmente presentada, debido a reparos del profesor guía, Martin Honecker, sobre el tipo de interpretación de la metafísica tomista contenida en ella. De todos modos, el libro fue publicado en 1939, causando una gran impacto ${ }^{3}$. Esta obra consiste básicamente en una interpretación de la metafísica del conocimiento de Tomás de Aquino, con apoyo en la relectura de corte kantiano desarrollada por el filósofo belga Joseph Maréchal y en algunas perspectivas fundamentales de la ontología existencial desarrollada por Martín Heidegger en los años veinte y en los primeros de la década siguiente (precisamente el período en que el joven Rahner lo conoció y siguió en Freiburg). A partir de todo ese entrecruce de influencias intelectuales ${ }^{4}$, nuestro autor desarrolla en esta obra una concepción del ser humano como "espíritu en el mundo". La expresión destaca su ser radicalmente abierto a la trascendencia, a la vez que el modo concreto e ineludible en que tal apertura se da, mediante un conocimiento en y a partir de la ex-

2 Sobre el desarrollo pneumatológico de la noción en el pensamiento del autor, cf. R. KERn, Theologie aus Erfahrung des Geistes - Eine Untersuchung zur Pneumatologie Karls Rahners (Tyrolia-Verlag, Innsbruck/Wien 2007).

3 K. Rahner, Geist in Welt. Zur methaphysik der endlichen Erkenntnis bei Thomas von Aquin (Felizian Rauch, Innsbruck/Leipzig 1939). Segunda edición en la Kösel-Verlag, München 1957, a cargo de J. B. Metz. La traducción al castellano, de Alfonso Álvarez, corresponde a esta edición: Espiritu en el mundo (Herder, Barcelona 1963). Las dos ediciones del original alemán han sido recogidas en las Sämtliche Werke de nuestro autor, Bd. 2: Geist in Welt. Philosophische Schriften, A. Rafflelt (ed.), Düsseldorf-Freiburg i. Br.: Benzinger-Herder, 1996.

4 Cf. K. Lehmann, "Philosophisches Denken im Werk Karl Rahners", en A. Raffelt (dir.), Karl Rahner in Erinnerung (Patmos, Düsseldorf 1994) 10-27; E. Coreth, E., "Philosophische Grundlagen der Theologie Karl Rahners", en Stimmen der Zeit 212 (1994) 525-536; E. Bautista Lucas, "Fundamentos filosóficos de la teología de K. Rahner”, en Efemérides Mexicana 43 (1997) 29-42; M. CHojnacki, "Erhelende Rückführung. Über das Ergreifen Karl Rahners Theologie mittels ihres philosophischen Hintergrunds”, en R. Siebenrock (dir.), Karl Rahner in der Diskussion. Erstes und zweites Innsbrucker Karl-Rahner-Symposin: Themen - Referate - Ergebnisse (Tyrolia, Innsbruck-Wien 2001) 171-188. 
periencia sensible que acontece en el mundo como ámbito de la materia y del devenir histórico.

Junto con esa perspectiva antropológica, en esta obra se manifiesta ya en Rahner una segunda impronta de su aproximación a nuestro tema, y que constituye lo más característico de su reinterpretación de Tomás de Aquino a través de los planteos de Maréchal en referencia a Kant: el así llamado enfoque "trascendental" (transzendentaler Ansatz). Esta perspectiva se basa en una comprensión del conocimiento no como simple "recepción" de un objeto por parte de un sujeto, sino como una experiencia a partir de determinadas condiciones de posibilidad en el sujeto mismo, de las cuales es necesario, en primer lugar, tomar conciencia ${ }^{5}$. La intuición básica es aquí, como veremos, la comprensión "inspirada también en la lectura de Tomás por parte de Pierre Rousselot" del conocer no como encuentro o "choque" entre realidades distintas, sino como despliegue del ser.

Una importante profundización de dicha interpretación de la metafísica tomista, Rahner la llevó a cabo en una segunda obra, Hörer des Wortes (en adelante $H W$ ), publicada en $1941^{6}$, a partir de algunos materiales previos ${ }^{7}$ HW lleva por subtítulo: "Fundamentos para una filosofía de la religión”, que expresa la intención de avanzar, siguiendo los impulsos de $G W$, en el desarrollo de una reflexión filosófica que, en su propia especificidad, se oriente finalmente a la fundamentación de una cuestión teológica, la experiencia del acontecimiento de la Revelación del Dios de Jesucristo, y, sobre todo, de las condiciones de posibilidad de este acontecimiento en el ser humano y en su ámbito concreto de existencia. Debido a este propósito fundamental de $H W$ es que se ha querido destacar aquí su relevancia para la conformación del pensamiento rahneriano.

5 En aplicación a la teología, Cf. K. RAHnER, "Überlegungen zur Methode der Theologie, en Schriften zur Theologie, Bd. IX (Benziger, Einsiedeln-Zürich-Köln 1970) 79-126; F. Berríos., "El método antropológico-trascendendental de Karl Rahner como hermenéutica teológica del mundo y de la praxis”, en Teología y Vida, Vol. XLV (2004) 411-437.

6 K. Rahner, Hörer des Wortes. Zur Grundlegung einer Religionsphilosophie (KöselVerlag, München 1941).

7 Cf. el texto resumido de las conferencias de Rahner en las "Semanas de la escuela superior de Salzburg” de 1937, y de una homilía pronunciada por él durante el evento, en $S W$, Bd. 4, 285-295. 
En 1963 se publicó una segunda edición reelaborada de $H W$, a cargo de Johann Baptist Metz ${ }^{8}$, discípulo de Rahner y entonces recién nombrado profesor de Teología Fundamental en Münster'. En su prólogo Metz se preocupa de explicar brevemente al lector cuál es la "idea fundamental" (Grundgedanke) de esta obra. Destaca que el título del libro remite a una "designación bíblica del ser humano" de cara a la revelación, designación que aquí se utiliza "en un esbozo de filosofía de la religión, que tiene afinidad con el pensar de santo Tomás, aunque sin ignorar las perspectivas (Ansätze) y problemas del quehacer filosófico actual (gegenwärtigen Philosophierens)" (3/10).

En la introducción del tomo 4 de las Sämtliche Werke de Rahner ${ }^{10}$ se recoge una carta fechada el 14 de noviembre de 1996, en que Metz aclara el alcance de su intervención. Destaca que todos los cambios en el texto fueron aprobados por Rahner, pero él como editor es el responsable directo del resultado final de la reelaboración. Por ejemplo, las notas a pie de página: la primera edición solo tenía una, en el capítulo 6. Pero la refundición más importante ya había sido señalada por Metz en dicho prólogo: el capítulo XIV de la primera edición fue eliminado como tal e incorporado al capítulo precedente. Hacia el final de este texto, Metz explica los cambios puntuales que él mismo estima más importantes, sin afectar al sentido general del libro, desde dos puntos de vista: teológico y ontológico. Ambos puntos de vista, y en especial el primero, tienen relación con el desarrollo del pensamiento del autor en los largos años transcurridos desde la primera edición ${ }^{11}$.

8 Para la citas textuales de esta obra indicaré primero (entre paréntesis, en el mismo texto y luego de la cita) la paginación de la versión original alemana de la segunda edición en las Karl Rahner Sämtliche Werke (SW), Bd. 4: "Hörer des Wortes. Schriften zur Religionsphilosophie und zur Grundlegung der Theologie”, A. Raffelt (ed.), Düsseldorf-Freiburg i.Br.: Benziger-Herder, 1997, y luego la de la traducción castellana de dicha edición (Oyente de la Palabra - Fundamentos para una filosofía de la religión, Barcelona: Herder, 1967). Utilizaré esta traducción, y la corregiré, indicándolo, cuando me parezca pertinente.

9 Cf. prólogo de la segunda edición, 3-7/ 9-12.

10 SW 4, XIII-XXXVIII, esp. XVI-XVII.

11 Cf. F. Taborda, "Ouviente da Palabra - Introdução a sua leitura”, en: P.R.F. DE Oliveira - F. TABORDA, Karl Rahner 100 anos: teologia, filosofía e experriência espiritual (Edições Loyola, Belo Horizonte 2005) 85-118. Sobre el texto de $H W$ en la edición de las Sämtliche Werke de Rahner, cf. C. ScHICKENDANTZ, “Karl Rahner: Obras Completas'. Una nueva situación en la investigación sobre Rahner”, en Teología y Vida, Vol. XL (1999) 416-438, esp. 427s. 
El propósito central del presente estudio es esclarecer la noción de "espíritu" en esta obra fundante del pensamiento rahneriano, en los parámetros de la antropología trascendental que lo caracterizará en todo su desarrollo (1.), para luego situarlo en el ámbito de su concepción de la libertad divina y humana (2. y 3.) y finalmente mostrar el "lugar" concreto en que, para Rahner, esta índole "espiritual” del ser humano acontece necesariamente (4.). Para el cumplimiento de estos objetivos, se ha privilegiado aquí un diálogo directo con el texto de $H W$.

\section{1. "ESPÍRITU” COMO NOCIÓN DE UNA ANTROPOLOGÍA FILOSÓFICA}

En tal horizonte, uno de los aspectos más interesantes de $H W$ es la ubicación epistemológica que Rahner lleva a cabo en la primera parte, junto con el planteamiento de la cuestión. ¿Qué tipo de texto es, finalmente, $H W$ ?

1.1 Presupuestos metafísicos: la unidad originaria de ser-conocer y la analogía de la posesión del ser

En continuidad con $G W$, su punto de partida es una metafísica. Más exactamente, la metafísica del conocimiento de Tomás de Aquino, releída con la ayuda de J. Maréchal en su diálogo con Kant, a partir de la noción de una unidad originaria de ser y conocer. Ser es conocer, y conocer es un estar el ente consigo mismo (bei-sich-sein). Pero hay diversos grados de ese estar consigo o de realización de lo que en filosofía escolástica se llama reditio in seipsum. Rahner nos pone ante la convicción básica de que solo el ente que es total y simple "posesión del ser" es, como bien lo sintetiza un buen conocedor de su obra, aquel que "posee ya de antemano, en absoluta identidad y pura transparencia, aquello por lo que habría de preguntar: el ser, sin más. Solo en él se identifican plenamente sery conocer en [su] unidad primigenia..." ${ }^{12}$. La noción precisa de "posesión del ser" (Seinshabe) como clave de comprensión o de interpretación del principio de la analogía del ser, es uno de los principales aportes de J. B. Metz en la segunda edición de $H W$. Esta nueva formulación habría sido considerada por el editor, con el acuerdo de Rahner, como más

12 J. L. Rodríguez Molinero, La antropología filosófica de Karl Rahner (Ediciones Universidad de Salamanca, Salamanca, 1979) 91. 
apropiada para expresar su concepción del ser como "ser-cabe-sî", en el sentido de subjetividad o reflectividad ${ }^{13}$.

En la parte segunda de $H W$ Rahner se esfuerza por demostrar la auténtica necesidad de una filosofía de la religión. Lo hace, también, siguiendo la metafísica de Tomás de Aquino (47/43; cf. 69/92) y retomando así conceptos fundamentales de $G W$. La metafísica habla de cosas "que se saben ya y que se han sabido siempre" (...); es "el conocimiento metódico reflejo de lo que se conocía ya desde siempre" (49/47). Por eso mismo, "la verdadera filosofía de la religión no es en último término otra cosa que la orden dada al ser humano, de prestar oído a su historia para ver si se ha dejado oír en ella la palabra de Dios" (loc. cit.). Además, la metafísica es una ciencia humana; la hacemos nosotros, personas concretas y limitadas. Se trata aquí, por tanto, de "una tentativa, permanentemente problemática, por captar en forma conceptual y científica el ser del hombre, en cuanto este es el sujeto de la posibilidad de creer, posibilidad que quizás poseemos ya debidamente en una forma previa y precientífica" (49s/48).

La metafísica es la pregunta por el ser del ente. En ella no basta detenerse en cuestiones particulares; es una pregunta "por los últimos fundamentos, por el fundamento único de toda realidad” (54s/50). Ya que se conoce a cada individuo como algo que es, entonces la metafísica es la pregunta por el ser de todo ente. Toda pregunta, tiene un "de dónde" (Woher) o "principio de una posible respuesta" (55/51), que en este caso es la pregunta misma, en cuanto parte necesaria y constante de la existencia humana. Ella está contenida en todo lo que el ser humano piensa o habla, y sin pensar o hablar no puede ser humano. Para Rahner, el preguntar metafísico, como nota distintiva del ser humano, es siempre,

13 J. L. Rodríguez Molinero, La antropología filosófica de K. Rahner, 90. Por lo mismo, llaman la atención los dichos de Metz en una reciente entrevista: "En ese tiempo vivía cerca de Karl Rahner en Nymphenburg, con las benedictinas [...] No escribí nada, realmente nada, que él no haya aceptado. Hoy estoy bastante triste por algunas cosas que incorporé y que él aceptó. Una palabra como 'Seinshabe' (posesión del ser), por ejemplo, hoy ya no la diría. Eso no estaba antes [en la primera edición]. Se dice una y otra vez: Metz siempre quiso ir un poco más allá, por ejemplo de la subjetividad a la intersubjetividad, y cosas así... Para todo Rahner me daba la autorización: hazlo, hazlo tú en las notas..." (A. BATTLOG - M. Michalski, [dir.], Begegnungen mit Karl Rahner. Weggefährten eirnnern sich [Herder, Freiburg i. B. 2006] 116-133, 117; traducción mía). En esta entrevista Metz no aporta otras explicaciones sobre este punto. 
necesariamente, una pregunta sobre él mismo, una "analítica del hombre" (59/53). Tiene tres aspectos: 1) es pregunta por el ser en general. 2) Debe ser una auténtica pregunta sobre el ser. 3) Es pregunta por el ser, distinguiendo en ello entre el ser y el ente. A partir de aquí, $H W$ se articula como el entretejido de tres "tesis de ontología general", a las que corresponden tres "tesis de antropología metafísica".

\subsubsection{La unidad originaria de ser y conocer como "estar consigo", luminosi- dad o subjetividad}

La primera tesis de ontología general (cf. 65/58) afirma que la esencia del ser es la unidad originaria de conocer y ser conocido, unidad que aquí es designada como un "estar-consigo", entendido a su vez como "subjetividad" o "luminosidad" (Gelichtetheit). La convicción básica es, como dijimos, el principio escolástico tomasiano de la identidad de conocer y ser. Por ello se entiende aquí que conocer es originariamente "subjetividad", antes que aquella "intencionalidad" propia de la relación de un cognoscente a un objeto distinto de él.

Ahora bien, si ser indica la unidad primigenia de conocer y ser conocido y si, por lo tanto, la subjetividad como un "estar consigo" es parte de la estructura del ser, al parecer no hay ningún ente que no implique a priori identidad de conocer y ser conocido. Esto, para Rahner, podría ser entendido como panteísmo o como alguna forma degradada de idealismo, y se propone demostrar que no es así.

\subsubsection{La analogía de la "posesión del ser"}

El punto de arranque de la tesis sobre la luminosidad del ser es que el hombre pregunta por el ser. Aquí Rahner hace la distinción entre "preguntabilidad" (Fragbarkeit) y "cuestionabilidad" (Fraglichkeit). Para preguntar se requiere que haya algo "preguntable" (fragbar) y por lo tanto "cognoscible" (erkennbar); pero además que aquello preguntado sea verdaderamente "cuestionable" (fraglich), es decir, que entre lo preguntado y el que pregunta haya una distancia, del tal manera que la pregunta no esté ya de antemano respondida.

El carácter cognoscible del ser es el que nos muestra a este como un "estar consigo", es decir, como una unidad primigenia de ser y conocer. Pero por otra parte está la afirmación de la "cuestionabilidad" del ser. ¿No suprime esta cuestionabilidad la cognoscibilidad del mismo ser? Es 
cierto que "el preguntante [...] solo puede saber del ser [...] en cuanto él mismo es lo sabido [...] Y sin embargo, el que pregunta 'no' puede 'ser' el ser por el que pregunta [...] El ente que pregunta es en este sentido no ser" $(73 / 64)$.

Por otra parte, acota Rahner, "este ente que pregunta debe 'poseer' (besitzen) ser, de ese al que se aplica la primera tesis" (73/65). Por tanto, el ser es una magnitud que no se puede entender unívocamente. Hay "grados" de estar consigo, de luminosidad o transparencia para consigo mismo, es decir, grados de "subjetividad". Y eso está en proporción con el "modo de tenencia del ser, es decir, con el modo en que el ser [...] conviene a un ente y en el que, por consiguiente, dicho ente 'tiene ser'" (loc. cit.). Se trata de un concepto analógico. Más exactamente, es analógica la forma en que cada ente retorna sobre sí mismo, puede estar consigo mismo y es "posesión del ser" (Seinshabe) ${ }^{14}$.

El paso siguiente es mostrar cómo esta mirada está presente en la metafísica del conocimiento de Tomás de Aquino, remitiendo de manera especial al capítulo IV,11 de la Summa contra gentes, en que el Aquinate se refiere a la variación de la reditio rei in seipsam como constitutiva de los diferentes "niveles del ser" (Seinstufen). A partir de este planteamiento, Rahner refuta la eventual interpretación panteísta de su primera tesis metafísica. Ser es conocer, pero no de un modo unívoco. El único que es absoluta 'posesión del ser' -en identidad del ente con su ser- como un "estar-consigo" es el ente que es "el puro ser", o sea, Dios (loc. cit., nota 46/7). En él, "la pregunta está siempre superada y rebasada ya por un saber que no admite pregunta... es la nóesis noéseos" (81/70). Distinto es en el hombre. La necesidad de preguntar por el ser es parte de su estructura fundamental, y en ello se manifiesta que es "espíritu finito" (endlicher Geist).

\subsection{El ser humano como "espíritu"}

Así se titula el capítulo $\mathrm{V}$ de $H W$. La expresión resume el segundo presupuesto para una posible revelación, a saber, que el ser humano tiene que poseer una "apertura" (Offenheit) a la automanifestación de

14 Cf. la nota de Metz sobre la aplicación del principio metafísico de la analogia entis como analogía de la "posesión del ser” (75/66, nota 40/1). 
$\operatorname{Dios}^{15}$ en su palabra (logos). Esta apertura tiene que ser a priori, para que tal palabra, si es dicha, pueda ser oída (83/73). Esta es precisamente la primera tesis de una antropología metafísica:

"el ser humano es la absoluta apertura al ser en general, o, para decirlo con una sola palabra: el ser humano es espíritu. La trascendencia hacia el ser es la constitución fundamental (Grundverfassung) del hombre" (83/73s).

Una revelación de Dios solo será posible si el sujeto al que ella se dirija posea en sí mismo y de por sí (von sich aus) un "horizonte apriórico" ilimitado para la misma. En otras palabras, una revelación "solo podrá concebirse como posible si se concibe al ser humano como espíritu, es decir, como el lugar $(O r t)$ de la trascendencia hacia el ser en general (auf das Sein schlechthin)..." (105/90).

\subsubsection{El porqué de la necesidad humana de la pregunta por el ser (o el ser humano como "sujeto")}

Se ha establecido que la pregunta por el ser en general surge necesariamente en la existencia humana, y que esta pregunta lleva implícita la respuesta, esto es, un cierto conocimiento del ser en general. El ser humano es sujeto, es decir, "está en un mundo de entes que se presentan como sus objetos" (83/74). En esa relación con las cosas del mundo, el ser humano las "juzga" (beurteilt) y así las distingue de sí. En una "salida aprehendente (erfassenden Ausgang) hacia las cosas, retorna el ser humano tan plenamente a sí mismo como 'sujeto' [...], que se halla en sí mismo como sujeto en contraposición (Gegenstellung) a una otra cosa conocida que está frente a él" (zu einem erkannten anderen gegen-stehenden Ding) (85/75). Aquí hay un juego de palabras que es en sí mismo elocuente: en alemán, "objeto" se dice Gegenstand; la expresión alemana das gegen-stehende Ding significa algo así como "la cosa objetual", en el sentido específico de una cosa que está ubicada "frente" al sujeto y de la cual este se diferencia radicalmente al "retornar a sí mismo".

Tomás de Aquino llama a esto reditio completa subiecti in seipsum, y es lo que distingue al espíritu de todo otro ente. Se manifiesta en todo

15 Como "fundamento absoluto de los entes y del conocimiento del ser" (15/20), "fundamento inobjetal de los entes" (loc. cit.) o "principio de todo ser y de la ciencia de él" (17/20). 
lo humano: sobre todo en el juicio y también en el obrar (Handeln). En el retorno a sí mismo mediante el juicio, el ser humano se hace libre, independiente del objeto conocido; y solo así y debido a ello puede obrar libremente con él. Este estar en sí mismo se manifiesta también y primariamente en la pregunta por el ser en general. Rahner se interroga: ¿cuál es la "condición trascendental apriórica de la posibilidad de esta subjetividad?” (87/77). Para responder, recoge un resultado preliminar de la pregunta por la esencia del ser humano: este es el primer ente "que puede realizarse como una reditio completa" (89/77). Por lo tanto, "la pregunta por el fundamento último de la posibilidad de este estar en sí mismo es [...] idéntica a la pregunta por el fundamento último o condición de posibilidad de trasponer a conceptos lo singular dado en la percepción sensible, de captar lo general en lo particular" (89/78).

El núcleo de esta problemática en la metafísica tomista se denomina "abstracción" (intellectus agens). Abstraer consiste en desgajar o separar el "qué", la quiddidad, del individuo particular en que se da. En este sentido, la abstracción es el conocimiento de lo ilimitado del "qué" que se da en un individuo concreto y que aparece así como "una nota que se extiende mucho más allá” del mismo (91/79). Ahora bien, ¿̨cuál es la "condición trascendental de la posibilidad" de que el cognoscente pueda conocer esto ilimitado de la quiddidad, si la ha experimentado en un individuo determinado? Condición "trascendental" quiere decir, en este contexto, a priori, o sea, anterior a todo conocimiento y a toda abstracción, como "condición previa" (vorgängig) de la posibilidad de estos.

\subsubsection{El rol de la "anticipación"}

El concepto de "anticipación” es aquí la denominación de aquel "extenderse". El "más" al que se refiere debe entenderse como "horizonte y fundamento último (gründerder Grund) de los objetos posibles y de su encuentro con ellos [...] la conciencia capta su objeto particular en una 'anticipación' [...] dirigida al ser" (93/80).

Así entendida, la anticipación es

"la condición de posibilidad del concepto universal, de la abstracción (...) Es una 'facultad' (Vermögen) -dada a priori con la esencia humana- del automovimiento dinámico (Selbstbewebung, cf. nota 51/4) del espíritu hacia el ámbito absoluto de todos los objetos posibles [...] En tal 'anticipación' se conoce ya siempre en cierto modo el ob- 
jeto particular bajo el horizonte del ideal absoluto del conocimiento" (93/81).

La anticipación no es por sí misma un acto de conocer, sino su condición de posibilidad. Con todo, solo se la puede concebir como conocimiento, ya que se extiende en forma de saber hacia algo que es objeto de conocimiento. Ese objeto es el ser y, en él, "el conjunto de los posibles objetos del conocimiento humano [...], en cuyo horizonte aprehendemos el objeto particular..." (95/83).

Por todo lo anterior, el principio de la trascendencia como constitución fundamental del ser humano en cuanto espíritu es la primera tesis de una antropología metafísica orientada a una filosofía cristiana de la religión como fundamento de la posibilidad de una revelación por la palabra $(\log o s)^{16}$. El ser es luminoso, es logos, y por ello puede ser revelado en la palabra; y el ser humano es espíritu, es decir, está dotado de una apertura que se manifiesta en su capacidad de "oír" toda palabra que pueda salir de la boca del Eterno. Establecida esta doble convicción, es necesario abordar una cuestión que ha quedado planteada desde el comienzo al tratar de describir el lugar de la noción de "espíritu" en el propósito de $H W$.

\subsection{Espíritu: ¿un concepto filosófico?}

Ha quedado claro que en Rahner "espíritu” es una noción eminentemente aplicada al ser humano, aunque concebida para expresar la apertura del mismo, de su ser finito y contingente, a la trascendencia, a lo infinito y absoluto. Por tanto, lo antropológico no se entiende aquí en un sentido restrictivo o cerrado, sino, por el contrario, en un horizonte de infinitud. En este punto se muestra Rahner como el pensador creyente que dialoga con la cultura moderna y su reivindicación del sujeto humano ${ }^{17}$, aunque a la vez superándola mediante un replanteo radical de esa concepción.

16 La nota 58/11 (páginas 105/91) indica los lugares en que se exponen las tesis segunda $(163 / 140)$ y tercera $(249 / 213)$.

17 "La teología de Rahner ha roto el sistema de la teología escolástica centrándola en el 'sujeto'. Su teología ha hecho emerger al 'sujeto' sacándolo de la roca del objetivismo escolástico en que por doquier se encontraba encerrada esta teología escolástica” (J. B. Metz, "Teología como biografía”, en Concilium 12 [1976] 209218, citado por R. Gibellini, La teología del siglo XX [Sal Terrae, Santander, 2a ed., 1998] 253). 
Mirado desde el conjunto de la obra de Rahner, el concepto "espíritu" debe comprenderse en el marco de una sensibilidad y de un pensamiento dominados por intereses teológicos. $G W y$ y $H W$ son obras en que Rahner desarrolla reflexiones propiamente filosóficas, aunque orientadas a la fundamentación de una visión teológica. Como bien ha precisado Renate Kern, en ellas se busca preparar, mediante el ejercicio del pensar filosófico (denkerisch), el terreno para la reflexión (nachdenken) de la fe ${ }^{18}$. En GWRahner se esfuerza por mostrar, con la ayuda principal del análisis marechaliano de la metafísica del conocimiento de Tomás de Aquino ${ }^{19}$, la unidad del conocimiento humano: mediante el conocimiento sensible y mundano, es decir, de lo finito y contingente, el ser humano se abre a lo infinito y a lo absoluto. Y dicho al revés: la trascendencia solo se le abre al ser humano mediante su referencia al mundo como concreto espacio de la materia y de la experiencia vital-sensible en el espacio y el tiempo.

Esta intuición de Rahner es, en último término, una versión especulativa del Leitmotiv de la espiritualidad ignaciana: "encontrar a Dios en todas a las cosas y a todas las cosas en Dios" ${ }^{20}$. Al hecho de la irrupción de Dios, en Jesucristo, en el mundo finito y su historia, corresponde la necesidad, ya filosóficamente señalada, de un volcarse al mundo, ahora con una fundamentación cristológica-encarnatoria y desde la experiencia de la fe. Así, "en el volcarse (Hinwendung) al 'aquí y ahora' de su

18 "Es geht darum, dem Glauben nach-zu-denken und denkerisch den Boden zu bereiten" (R. Kern, Theologie aus Erfahrung des Geistes, 82).

19 Cf. O. Muck, "La Escuela Marechaliana de lengua alemana: la filosofía trascendental como metafísica”, en E. CORETH y otros (dir.), Filosofía cristiana en el siglo XIX y XX, tomo 2: Vuelta a la herencia escolástica (Ed. Encuentro, Madrid 1994) 540-570.

20 La formulación como tal no se encuentra en el texto de los Ejercicios Espirituales de San Ignacio de Loyola, pero sí otras parecidas, en especial en la "Contemplación para alcanzar amor": "[...]mirar cómo Dios habita en las criaturas, en los elementos dando ser, en las plantas vejetando, en los animales sensando, en los hombres dando entender; y así en mí dándome ser, animando, sensando, y haciéndome entender; asimismo haciendo templo de mí seyendo criado a la similitud y imagen de su divina majestad [...]" (EE. EE., n. 235). Claramente, es una idea fuerza de esta espiritualidad, que Ignacio reiteró repetidas veces en su correspondencia y en las mismas Constituciones de la Compañía de Jesús; un ejemplo: "Y sean exhortados a menudo a buscar en todas cosas a Dios nuestro Señor, apartando, cuanto es posible, de sí el amor de todas las criaturas, por ponerle en el Criador de ellas, a Él en todas amando y a todas en Él, conforme a la su santísima y divina voluntad" (Const., 288). 
mundo, el ser humano se remite a su conocimiento objetal (Gegenstandserkenntnis), así como a la apertura (Erschließung) de Dios mismo en la historia" 21 .

Un aporte significativo de $H W$ es haber un dado un paso adelante con respecto a la metafísica del conocimiento desarrollada en $G W$. Con expresiones del propio Rahner, este paso ha consistido, básicamente, en mostrar que el ser humano, por su propia constitución esencial, puede prestar libre oído a una libre revelación de Dios posiblemente acontecida en la historia. Lo que en $G W$ se desarrolla como una metafísica del conocimiento, en $H W$ avanza hacia la fundamentación de una filosofía de la religión entendida como un análisis de la esencial potentia oboedientialis humana, es decir, de su necesaria capacidad de "receptividad" (Empfänglichkeit) de una eventual y siempre libre automanifestacion personal de Dios en la historia ${ }^{22}$. El elemento transversal que une los empeños de ambas obras, entre sí y en su orientación al pensamiento teológico posteriormente construido por Rahner, es lo antropológico como fundamento y punto de partida imprescindible para la comprensión de la revelación como acontecimiento salvífico.

En esta comprensión del pensamiento rahneriano, un aspecto especialmente importante es cómo han sido vinculadas en él filosofía y teología $^{23}$. En $G W$ y en $H W$ vemos una primera definición de esta relación ${ }^{24}$. En $H W$, la manera de entender este vínculo, y específicamente a partir

21 R. Kern, Theologie aus Erfahrung des Geistes, 82.

22 Cf. Th. Knieps-Port le Roi, "Zum nach-neuzeitlichen Ort der Theologie. Überlegungen zum Verhältnis von Glaube und Vernunft nach Karl Rahner 'Hörer des Wortes", en R. SiebenRock (dir.), Karl Rahner in der Diskussion. Erstes und zweites Innsbrucker Karl-Rahner-Symposion: Themen - Referate - Ergebnisse (TyroliaVerlag, Innsbruck-Wien 2001) 203-224.

23 Cf. M. Lutz-Bachmann, “'Die Theologie bedarf der Philosophie’. Über einen Grundsatz der Theologie Karl Rahners", en M. Delgado, M. M. Lutz-Barchmann (dir.), Theologie aus Erfahrung der Gnade. Annährung an Karl Rahner (MorusVerlag, Berlin1994) 284-298, 285.

24 Otras aproximaciones de K. RaHner a este tema: "Philosophie und Theologie", en Schriften zur Theologie, Bd. VI (Benziger, Einsiedeln-Zürich-Köln 1965) 91103; "Der Mensch von heute und die Religion", en Schriften zur Theologie, Bd. VI (Benziger, Einsiedeln-Zürich-Köln 1965) 13-33; "Philosophie und philosophieren in der Theologie", en Schriften zur Theologie, Bd. VIII (Benziger, EinsiedelnZürich-Köln 1967) 66-87. 
de la pregunta sobre la posibilidad de una filosofía "cristiana" 25 , enmarca en cierto sentido todo el contenido del libro. Por ello, en el capítulo último y conclusivo Rahner vuelve sobre ciertos planteamientos iniciales sobre el respecto, para afirmar que una filosofía puede ser cristiana no porque la teología la preserve como "norma negativa" o la obligue a considerar problemas teológicos en una perspectiva metafísica, sino por la "superación" (aufheben) de sí misma en favor de una teo-logía.

A este respecto hay que volver a lo que Rahner había explicitado en los comienzos de $H W$ acerca de una doble acepción del concepto de teología. En su "esencia originaria" la teología es "la escucha iluminada (gelichtetes Hören) de la revelación que Dios hace de Sí mismo, conforme a su libre designio, por medio de Su Palabra" (17/21). Esto quiere decir que en su sentido primero (ursprünglich) la teología no es un discurso humano, sino antes bien "la totalidad (die Gesambeit) del hablar (Rede) divino dirigido por Dios mismo al hombre, si bien en lenguaje humano" $(17 / 21 s)$. Este es, para él, el significado originario de la teología y su "primer sentido", vale decir, "teología positiva". En un segundo sentido, la teología consiste en que una vez oída la revelación libremente hecha por Dios acerca de Sí mismo, "el ser humano puede hacerla objeto de su pensar que interroga, sistematiza y coordina en el complejo total del saber humano" (17/22). Esto es lo que Rahner llama aquí la "teología escolástica". La teología escolástica "se basa esencialmente en la libre palabra de la revelación de Dios mismo (es decir), en la teología que oye la palabra de Dios, en la teología positiva" (loc. cit.). En consecuencia,

"una fundamentación científica de la teología, que en algún modo por lo menos debe concebirse como anterior a esta, no puede extenderse a la palabra de Dios, sino que debe ceñirse a la audición de la palabra por parte del ser humano: solo a la posibilidad apriórica de la capacidad de escuchar (Hörenskönnen) una revelación de Dios que posiblemente ocurra" (19/22).

Rahner se pregunta si no "llega tarde" la teología con respecto a la filosofía de la religión, en lo que respecta al "efectivo escuchar la revela-

25 Cf. E. Coreth, "Introducción a toda la obra", en: E. Coreth y otros (dir.), Filosofía cristiana en el siglo XIX y XX, tomo 1: Nuevos enfoques en el siglo XIX (Ed. Encuentro, Madrid 1993) 23-28; Schmidinger, H. M., "Historia del concepto de 'filosofía cristiana'”, en E. CORETH y otros (dir.), Filosofía cristiana en el siglo XIX y $X X$, tomo $1,29-45$. 
ción de Dios realmente ocurrida” (23/26). Parecería así que la teología tendría que limitarse a "dar el último retoque (...) a la relación entre el ser humano y Dios, fijada ya en sus líneas fundamentales por la filosofía de la religión" (loc. cit.). A esto Rahner trae a colación una precisión de gran importancia: la teología existe y se remite al hecho de la revelación como acontecimiento histórico; un hecho que el ser humano no maneja ni crea. En cambio, la filosofía de la religión, por su enraizamiento en la metafísica, parece ser por esencia "supratemporal" o "suprahistórica". Considerado ello, para Rahner la filosofía de la religión no puede tener como propósito el delinear por sí misma una religión que luego la teología solo tendría que "seguir" o "completar". La filosofía de la religión tiene más bien que "remitir al ser humano a una eventual revelación Dios (...) que, si se produce, se producirá históricamente" (25/27). Y si se da tal revelación histórica, entonces esta ya sería una cuestión de la teología, en su doble acepción.

1.4 .Espíritu" en el contexto de una filosofía de la religión con ribetes de antropología teológico-fundamental

Finalmente, todo esto remite a "una cuestión de antropología". Con este enfoque se está diciendo que la metafísica, "que en sí misma es ya filosofía de la religión", debe reconocer a Dios como "el Desconocido libre" (der freie Unbekannte, 25/27) y al ser humano como un "ser histórico por su subjetividad trascendental” (loc. cit.), y que por tanto debe remitir a este a la historia y determinarlo a prestar allí oído a una eventual revelación de ese Dios. En este sentido, esta metafísica-filosofía de la religión antecede a la teología, pero la antecede "para hacerle sitio" (27/28). Se trata de una "fundamentación (Begründung) preteológica posible de la teología” (27/29). En consecuencia, hay que decir que la cuestión de la relación entre ellas es finalmente "la cuestión de una antropología metafísica” que debe comprender la naturaleza del ser humano en una doble forma: 1) como espíritu, puesto que se halla esencialmente ante el Desconocido libre y debe contar siempre con una posible revelación de este Dios; y 2) como espiritu que existe concretamente en la condición histórica del ser humano (29/29).

Se trata, por tanto, para Rahner, de una filosofía de la religión como antropología metafísica que es, más exactamente, antropología "teológico-fundamental" (261/221), es decir, una antropología teológica en el sentido específico de una autocomprensión no refleja del ser humano 
como condición de posibilidad de la teología, entendiendo a esta en su sentido primigenio de teología "positiva": "el simple escuchar el mensaje de Dios" $(259 / 220)^{26}$. Oír la revelación presupone una determinada constitución fundamental del ser humano y tiene que ser afirmado como un oír libre. Además, la palabra de Dios, para poder ser oída por el ser humano, tiene que ser dicha como palabra humana, o sea, como palabra comprensible dentro de dicha constitución. Esta filosofía de la religión es, entonces, antropología "teológico-fundamental", porque la autocomprensión del ser humano que en ella se manifiesta es "el presupuesto (Voraussetzung) para que el hombre esté siquiera capacitado para oír la revelación efectivamente ocurrida" (263/222).

Con la misma convicción subraya Rahner que esta antropología es filosofía de la religión en sentido propio, ya que trabaja con los medios propios de esta disciplina y define a la religión desde el punto que le es accesible: "la esencia irrevocable (unaufhebbar) del ser humano, de su propio mundo que lleva necesariamente consigo y de las leyes formales fundamentales [...] del pensar" (263/223). La filosofía de la religión conlleva una antropología metafísica, aunque ambas disciplinas no son lo mismo. Para cultivar a aquella, "el ser humano debe haberse aprehendido a sí mismo como espíritu. Porque solo así podrá saber lo que es propiamente, analógicamente, 'posesión del ser' [...]” (265/224s).

La filosofía de la religión tampoco es lo mismo que la teología, pero sí es "la disciplina que constituye la disposición (Bereitschaft) para [esta] y, como tal, su necesario presupuesto (Voraussetzun); es la que constituye la potentia oboedientialis para la revelación..." (269/227). Y esta revelación puede ocurrir por la palabra o por el silencio de Dios, ambos en $\mathrm{Su}$ plena libertad.

De todo esto Rahner concluye que puede haber filosofía "cristiana" en cuanto preparatio evangelii. No por un "bautismo posterior" (nachträgliche Taufe), sino por el hecho de concebir (bilden) ella misma un ser humano que puede oír el mensaje de Dios...” (273/230). Por una parte, esta comprensión muestra la "receptividad (Empfänglichkeit) positiva" del ser humano a la revelación, la cual no es ya entendida como "contragolpe o repercusión dialéctica negativa" ni como pura "crisis"

26 Cf. W. Werner, Fundamentaltheologie bei Karl Rahner - Denkwege und Paradigmen (Francke Verlag, Tübingen/Basel 2003) esp. 64-73 y 188-192. 
(en el sentido de "juicio") de Dios sobre lo humano y lo intramundano (Karl Barth, 275/231). Por otra parte, tal receptividad no aparece como una realización inmanente de una "exigencia" religiosa del ser humano; no tiene a Dios como correlato inmanente necesario (Schleiermacher, $\left.275 / 231^{27}\right)$.

\section{ESPÍRITU FINITO - ESPÍRITU INFINITO: ENTRE LA “ANTICIPACIÓN” Y EL ESTADO DE OCULTAMIENTO DEL SER}

Consecuentemente, la segunda tesis de ontología general plantea que el ser absoluto de Dios es, frente al ente finito, el ser libre (cf. 143/124).

\subsection{Espiritualidad, anticipación y ocultamiento del ser}

En la parte tercera de $H W$ Rahner contrasta la apertura y luminosidad del ser, la "naturaleza espiritual" (Geistigkeit) y la "anticipación", antes destacadas, con el "estado de ocultamiento del ser", que es propio de la suprema libertad de Dios como ente de la plena "posesión del ser". Por esta determinación, Dios es caracterizado como el "Desconocido" (Cap. VII). Afirmar la apertura absoluta al ser en general como condición ontológica trascendental del hombre, podría llevar finalmente a cuestionar el carácter libre e indebido de la revelación del ser absoluto de Dios. Podría parecer que "no puede darse una revelación como libre desvelamiento de algo en sí esencialmente oculto, por la sencilla razón de que todo está ya por principio manifiesto de antemano y por tanto no tiene necesidad de ser manifestado mediante revelación" (109/96s).

Desde el punto de vista antropológico, surge la pregunta de cómo se pueda "explicitar la esencia del ser humano de tal forma que no obstante su trascendencia al ser en general y no obstante la intrínseca luminosidad del ser, esta trascendencia no adelante $^{28}$ el contenido de una posible

27 Cf. Cap. II, 45/41. Esta doble identificación está en F. TABOrDA, “Ouviente da Palabra...", 99, en contra de lo anotado por Metz en la nota 23/8 (45/42) en dicho capítulo.

28 Traducción corregida. El original dice: vorwegnimmt, del verbo vorwegnehmen (que también significa anticipar); es decir, no utiliza el verbo vorgreifen, del que deriva el sustantivo Vorgriff. Para no afectar la relevancia que Rahner le da a la noción de anticipar-anticipación mediante el uso de estos términos específicos, se ha preferido aquí traducir al castellano con otro verbo. De hecho, la naturaleza "espiritual" del ser humano "anticipa", pero no "posee por adelantado" la revelación como libre autodonación o automanifestación de Dios, así como el ente finito "anticipa” pero 
revelación, y así siga siendo posible la libre automanifestación del Dios personal" (111/98). En otras palabras, hay que responder a la cuestión de "por qué el ser, pese a su luminosidad y en ella, es sin embargo lo más oculto (das Verborgenste)" (113/99).

2.2 La contingencia como punto de partida de la pregunta por el ser y la voluntad como momento intrínseco del conocimiento

El punto de partida de la pregunta por el ser es, en $H W$, el carácter absoluto de lo contingente en cuanto tal: al ser humano le es necesario preguntar, dado que no conoce todo. No es ser absoluto, de absoluta luminosidad, de absoluta "posesión del ser" (125/110). En cuanto el hombre puede preguntar -dada la "preguntabilidad", Fragbarkeit, y la consecuente "cognoscibilidad", Erkennbarkeit, del ser-, afirma su finitud y contingencia; y en cuanto tiene que preguntar -dada la "cuestionabilidad", Fraglichkeit, del ser, es decir, la distancia que muestra que el ser humano no conoce todo-, afirma necesariamente esa contingencia. La afirmación absoluta de la contingencia es la voluntad y "[...] la apertura del ser para la existencia es efectuada por la voluntad como momento intrínseco del conocimiento mismo" (131/114).

La afirmación necesaria de la contingencia por la voluntad manifiesta que aquello que es afirmado de ese modo está constituido por "otra voluntad", y así se puede comprender a aquella afirmación voluntativa como el asumir y el replicar (Nachvollzug) esa "otra voluntad". Ahora bien, el Dios libre es desconocido. Dios es la meta, el hacia dónde (Woraufhin) de la anticipación del espíritu humano, como poder libre frente a lo finito. El ser humano está como espíritu frente al ser absoluto “personal”. La persona no se conoce a menos que ella se abra en un acto voluntario. Ya en la pura condición creatural el ser humano está siempre delante de un Dios de la revelación que actúa en la historia, porque es libre. Para que además de la creación haya "otra" revelación, se requieren dos condiciones: 1) que Dios no haya agotado sus posibilidades de acción libre frente a su creatura, al crear. 2) Que la creatura haya tenido lugar para recibir conocimientos. En cuanto que no se da todavía la visión inmediata de Dios, hay lugar para recibir otra revelación de Dios libre.

no "tiene" por adelantado al ser en plenitud, sino solo en la medida de su "posesión del ser". 


\section{EL ESPÍRITU FINITO COMO EL “OYENTE LIBRE"}

¿Qué es el hombre frente a la libertad de Dios como ser absoluto? Es la pregunta que a continuación $H W$ debe responder. A la segunda tesis de ontología general (el Ser Absoluto es el ser libre con relación al ente finito) corresponde la segunda tesis de antropología metafísica: el ser humano está libremente a la escucha del Desconocido libre.

\subsection{Espíritu finito: voluntad y afirmación de la propia contingencia}

En este marco Rahner destaca nuevamente el "momento voluntativo del conocimiento” que se da en el espíritu finito. Esto, para él, corresponde al contenido de una tesis "obvia para una ontología tomista", a saber, que "puesto que ser es siempre espíritu y voluntad, verum et bonum, el conocer -que es ser, y solo como ser es conocer- no se puede comprender adecuadamente en su propia esencia sin que al mismo tiempo se comprenda también como voluntad" (143s/125).

Esto se traduce en el ser humano en la aceptación y afirmación de su propia existencia como contingente. La contingencia aparece en principio como incomprensible. Algo es comprensible en la medida en que está positivamente en el contexto del ser como su fundamento. Es decir, solamente es comprensible el ser absoluto de Dios (en cuanto meta a que apunta la anticipación), o bien el ente finito particular, comprendido como fundado en el ser absoluto de Dios. De lo contrario, este ente particular no podría ser "comprensible", porque la comprensibilidad implica necesariamente la inserción en el horizonte absoluto de los posibles objetos de conocimiento. Para que se dé esa inserción, es necesario que el ente particular sea él mismo ese horizonte absoluto de conocimiento, lo cual no es posible para el caso del ente finito; o bien que él sea comprendido como vinculado por sí mismo con el horizonte de conocimiento, es decir, que tenga su fundamento en el ser absoluto de Dios.

\subsection{Luminosidad del ser, amor y libertad del ser humano}

Para Rahner el conocimiento consiste en un "estar consigo" del ente en su ser (149/128). Si este estar consigo, esta posesión de sí, es perfecta, entonces el conocimiento es pleno. Por su parte, el acto libre no es primariamente un acto que tenga que ver con algo distinto, algo extraño a la acción misma, sino que es más bien "realización de la propia esencia, toma de posesión de uno mismo [...] es el actuante mismo" (149/129). 
Por lo mismo, el acto libre es luminoso en sí mismo; es oscuro solo para el conocimiento que quiere comprenderlo sin inmiscuirse, sin involucrarse en él, manteniéndose fuera. Para comprender el acto libre es necesario participar de su realización (mitvollziehen, loc. cit.), en cierto modo replicándolo (nachvollziehen). Solo de este modo el ser libre puede estar presente para sí, ser-cabe-sí, y así comprender.

El concepto de luminosidad, considerado aquí desde el punto de vista de la libertad, muestra la compatibilidad de esta con la comprensibilidad. La comprensibilidad es "la capacidad de inserción (Einfügbarkeit) en el contexto fundamentante del ser (in den gründenden Seinszusammenhang)"(149/130). Lo finito tiene su fundamento en la acción libre y luminosa de Dios, que es amor. De este modo, el amor deviene la lámpara del conocimiento de lo finito y, como solo conocemos lo infinito a través de lo finito, es la luz de todo nuestro conocimiento. El conocimiento es, así, "la claridad luminosa del amor (die lichte Helle der Liebe)" (151/131). Si no fuera así, el conocimiento devendría oscuridad, convirtiendo lo contingente en necesario o dejándolo en incomprensibilidad absoluta. Ya que Dios ama libremente como potencia creadora de lo finito, "amando comprende lo finito mismo" (151/131) y así lo finito tiene "participación en la luminosidad del ser" (loc. cit.).

\subsection{El ser humano, espíritu en libertad}

Con esto se procede a desarrollar el tema de la libertad en y del ser humano. La afirmación necesaria de lo contingente por parte del ser humano es la reproducción (Nachvollzug) del poder luminoso creador de Dios libre. El hombre es, por su constitución fundamental, "el ente que se halla ante el Dios libre, el Dios de una posible revelación” (153/132). Ahora bien, esta posición el ser humano la adopta por "una actitud (Verhalten) voluntaria (e incluso necesaria) para consigo mismo [... y] en el fondo una actitud para con Dios" (loc. cit.). Tal es, para Rahner, el significado de la segunda tesis de antropología metafísica: "el ser humano es el ente que con un libre amor se halla ante el Dios de una posible revelación” (163/141).

En la trascendencia del ser humano al ser y al bien está implícita la afirmación necesaria del bien absoluto. ¿Podría la libertad particular contradecir dicha afirmación? Sí. La decisión particular puede actuar sobre la apertura fundamental no aniquilándola, pero sí dirigiendo a la 
persona y formando su propio orden del amor, que de hecho puede ser contrario al establecido por Dios. En otras palabras: la trascendencia hacia Dios del ser humano concreto contiene siempre, como un momento interno, una decisión libre.

\section{LA TRASCENDENCIA DEL ESPÍRITU FINITO “EN EL MUNDO”}

A partir de esta ubicación de la posibilidad del encuentro revelador del ser absoluto con el hombre como espíritu en el horizonte de la libertad, se procede a responder a la pregunta acerca del "lugar" en que debería acontecer tal evento.

\subsection{Trascendencia en la "anticipación"}

En la "anticipación" acontece la trascendencia radical del ser humano en cuanto "espíritu". Así, en $H W$ se sientan las bases principales de la concepción rahneriana de la trascendentalidad de la trascendencia, que a su vez llama a precisar la mediación categorial de lo trascendental. Lo que está detrás es una determinada manera de concebir la relación entre trascendencia e inmanencia, que, por una parte, busca distanciarse del extrinsecismo que el jesuita reprochó a la neoescolástica, y, por otra parte, pretende comprender la inmanencia histórica de modo tal que se supere una comprensión de lo mundano como ámbito ciego o cerrado en sí mismo ${ }^{29}$.

4.2. El ser absoluto de Dios como "horizonte" y fundamento de la apertura infinita del espíritu finito

Por ello, la anticipación debe ser entendida ante todo como el horizonte absoluto de la índole espiritual del ser humano, es decir, como experiencia de atisbo de lo ilimitado precisamente en la experiencia del límite, en los parámetros de la historicidad.

\subsubsection{Anticipación y experiencia trascendental del limite}

¿Qué es exactamente aquella "totalidad" a la que trasciende el conocimiento "anticipante" humano cuando aprehende el objeto particular? En otras palabras, ¿de qué modo concreto tiene lugar la anticipación?

29 Cf. F. Berríos, "Teología trascendental y praxis. Una reflexión desde el legado de Karl Rahner”, en Teología y Vida, Vol. XLIII (2002) 467-502. 
Entre diversas posibles respuestas, Rahner toma y profundiza la de la escolástica: la anticipación tiene lugar en cuanto la experiencia trascendental del "no", del límite, aparece como "el modo en que está presente la absoluta positividad, sustrayéndose continuamente y, así, atrayendo del mismo modo (gerade) al espíritu" (95s/83). El conocimiento humano se dirige primariamente al ente, es decir, al "sí", al ser y no a la nada. En consecuencia, es "posible y legítimo (können-dürfen) no interpretar la trascendencia como una trascendencia a la nada" (97/84). La anticipación, por el contrario,

"apunta a lo ilimitado [...] es en sí misma la negación de lo finito [... es] condición de posibilidad del conocimiento de lo finito [porque], al superarlo y trascenderlo, eo ipso pone de manifiesto su finitud. Por tanto, el sí que se da a lo de suyo ilimitado posibilita la negación, y no al revés $[\ldots]$ La ilimitación positiva del horizonte trascendental del conocimiento humano muestra ya por sí misma la finitud de todo lo que no cubre completamente este horizonte. No es que la nada 'nihilice', sino que la in-finitud del ser al que apunta la 'anticipación' desvela (enthült) la finitud de todo lo inmediatamente dado" (97/84).

De este modo, “la 'anticipación' - que condiciona trascendentalmente [...] la posibilidad de estar el ser humano en sí mismo- es una 'anticipación’ del ser en sí ilimitado" (99/85).

\subsubsection{Dios, "el ente de la absoluta 'posesión del ser"”}

Con ello se reafirma a Dios como "el ente de la absoluta 'posesión del ser” (99/86). No es que la anticipación ponga a Dios como objeto del espíritu, pues aquella es solo condición de posibilidad del conocimiento objetal. Pero en la anticipación sí se afirma, aunque no se represente propiamente, la existencia de un ente de absoluta 'posesión del ser', esto es, Dios (loc. cit.), puesto que "la positividad del ser es la que posibilita el 'no' de la diferencia ontológica inacabada (unvollendet), y no al revés. Por esto se puede decir que la 'anticipación' tiene por meta (zielt auf) a Dios" (99s/86). Pero no como objeto, sino como horizonte absoluto. La afirmación de la finitud de un ente exige, como condición de posibilidad, "la afirmación de la existencia de un ens absolutum, afirmación ya implícita en la 'anticipación' del ser en general, gracias a la cual se conoce como tal la limitación del ente finito" (loc. cit.). 
En términos tomasianos, la abstracción o entendimiento agente sería "la facultad de la 'anticipación' del esse" (101/88) y la luz (lumen) que, penetrando el objeto dado a la sensibilidad, le da forma, es decir, "lo sitúa dentro de la esfera del ser en general, permitiendo que de esta manera se conozca su participación en tal ser...” (loc. cit.). De ahí aquello de De Veritate 22,1: "Todos los cognoscentes conocen implícitamente a Dios en cada conocimiento" (citado en 103/88).

\subsection{El carácter histórico y material del ser humano como espíritu}

Este es el tema central de la parte cuarta de $H W y$, en cierto sentido, de toda la antropología rahneriana. De lo que se trata aquí es de plantearse cuál sería el "lugar" de una revelación, en el caso de que el Desconocido libre decidiera decir una palabra ${ }^{30}$. Para ello, Rahner fija tres perspectivas (Einsichten) importantes: la primera, que el "lugar" (Ort) de una posible revelación de Dios no puede limitar a priori las posibilidades de dicha revelación, dado que el ser humano, en cuanto trascendencia ilimitada, no posee una ley a priori que pueda delimitar el posible objeto de una revelación. La segunda perspectiva es que la manifestación categorial de un desconocido puede acontecer de dos maneras: a) presentándose en su propia identidad (in seinem eigenen Selbst: 171/149); o bien b) por la mediación de un conocimiento de él mismo en la palabra, entendiéndose por esta "un signo que representa lo que no se da en su misma identidad" (loc. cit.). Por lo tanto, en cuanto Dios no se presenta inmediatamente (o sea, como visio beatifica), el ser humano debe contar con la posibilidad de una revelación de este Dios en la palabra. Por último, una tercera perspectiva es que el "lugar" de una posible revelación no se puede definir de antemano de tal modo que se designe así una "parte determinada" de la constitución fundamental del ser humano, la que en cuanto tal sería el lugar privilegiado (bevorzugte) de tal revelación.

30 La nota 1 del capítulo IX remite a la nota 8 del capítulo I, que hace la distinción entre la trascendentalidad espiritual (subjetividad) y la "elevación" o "iluminación" de esa trascendentalidad por la gracia (el existencial sobrenatural). Según esta distinción, la revelación consiste en dicha iluminación o elevación más su exposición categorial en la palabra histórica. Esto, para evitar dos posibles interpretaciones del "lugar" de la revelación: 1) una interpretación "natural y ahistórica"; y 2) una interpretación que implique un reduccionismo a la trascendentalidad (aunque agraciada) del ser humano solo. 
Por otra parte, Dios solo puede revelar lo que el ser humano puede oír. Entonces, para encontrar ese "lugar" de la posible revelación es necesario determinar lo específicamente humano de la trascendencia humana. Ya no basta afirmar que el ser humano es "espíritu finito" (su trascendencia); hay que precisar la forma concreta en que lo es (173/151). Y la respuesta aquí es que el hombre es espíritu como ser histórico. Por lo tanto, el "lugar" de su trascendencia no puede sino ser, también, histórico.

\subsubsection{El ser humano es, por esencia, histórico}

Cierta historicidad de una posible revelación resulta de una ontología general. Ya que el ser humano conoce a Dios como el ente de la absoluta "posesión del ser", se le aparece por tanto como Aquel que obra libremente. Y este obrar libre es "ya en un sentido esencial un obrar histórico [...] hay historia dondequiera que se pone algo libremente, es decir, cuando sucede algo que no se puede deducir ni prever [...] Tal acontecer libre, indeducible, es siempre algo original, único e irrepetible, algo inteligible solo en sí mismo, algo que no es meramente un caso de una ley general". (175/151). En este sentido, la revelación, "vista desde Dios, se muestra ya como un acontecimiento histórico" (175/152). Pero este acontecimiento no es solo histórico, sino que además está revestido de lo propio de la historicidad humana. En efecto, "el tornarse hacia su historia es un momento intrínseco de la condición espiritual del ser humano" (177/153).

\subsubsection{Ser es conocer, como un conocimiento "receptivo"}

Si ser es conocer como un "estar-consigo", no como un mero aprehender algo distinto al sujeto, el conocimiento humano tiene a la vez la estructura metafísica de un conocimiento "receptivo", tanto en lo que atañe a la facultad que recibe como al objeto recibido, puesto que conocer y ser conocido forman una unidad interna (179/155). Es decir, la reditio, la subjetividad, solo es posible mediante la salida hacia otro diferente. Este punto Rahner lo profundiza en el capítulo X de $H W$.

Ahora bien, si conocer es un "estar consigo" del ente cognoscente, ¿cómo puede acontecer ello en un volcarse hacia otro? Rahner observa: se puede conocer algo distinto del cognoscente, cuando un ente se aprehende a sí mismo como causa y principio de algo otro; por ejemplo, 
Dios, ser de absoluta posesión del ser, que aprehende su propia esencia en cuanto todopoderoso principio creador de seres finitos. De todos modos, el texto intenta una primera respuesta "formal" a esa aparente aporía: Si el cognoscente tiene su ser como ser de otro, al estar presente a sí mismo por el conocimiento estará presente al otro, "conociendo en otro". De este modo, en la reflexividad sobre sí, lo primero conocido es lo otro, en lo cual el cognoscente ya estaba; pero no por el conocimiento en cuanto tal, sino "entitativamente" (seinsmäßig) (185/161).

\subsubsection{El ser del hombre es el ser de la materia como principio metafísico "de individuación"}

¿Qué es y cómo ha de ser aquello "otro"? Debe ser real, aunque no 'ser'..." (185/162), o la "posibilidad subjetiva (subjekthafte Möglichkeit)" de ser. Así, el ser del hombre es ser de una posibilidad o potencia de ser (Seinsmöglichkeit) "vacía, indeterminada, subjetiva, distinta realmente de él” (187/162). A esta potencia se la llama materia en la metafísica tomista; material en un sentido metafísico y no en el sentido moderno de materialidad física/química.

El ser del hombre es "el ser de esa indeterminada posibilidad real a la que se llama materia" (187/163). En terminología de Tomás: Anima humana est forma corporis, entendiendo "cuerpo" en su sentido tomista estricto, es decir, como "materia prima", como la "vacua potencia real de ser" (loc. cit.). El conocimiento humano es receptivo, de tal forma que para aprehenderse el hombre a sí mismo escientemente, tiene la necesidad de salir al mundo, de aprehender algo otro distinto a él. El ser del hombre es "la recepción de un objeto, no la posesión apriórica de un conocimiento que le venga de sí mismo, es ser de la materia" (189/165). El "conocimiento sensible" (sinnliche Erkenntnis) es propio del conocimiento receptivo del ser humano. La esencia metafísica de la sensibilidad radica en que ella "es el conocimiento que posee todo ente que, para tener lo otro como su primer objeto, ha de ser también, por su parte, ser de la materia” (189s/165).

$H W$ se empeña en mostrar la esencia de esta materia. El tercer aspecto de la pregunta metafísica nos indica que el ser humano conoce el ser siempre como el ser de un ente, es decir, como quiddidad (Washeit) de un "otro". Además, distinguiendo en cada objeto de nuestro conocimiento entre un "qué" (Was) que se da en un "algo" (Etwas), y este "algo" deter- 
minado por esa quiddidad. Ese "algo" no puede ser Ser en sí, pues en ese caso sería aprehensible por sí, luminoso en sí; es decir, sería quiddidad de algo. Ese "algo" solo puede ser "la vacua posibilidad indeterminada, subjetiva, de la 'posesión del ser” (193/167). Ese "algo", visto en relación al conocimiento humano receptivo, es la materia.

Así, la quiddidad se muestra siempre en el juicio como lo universal; la materia, como "el soporte indeterminado que por sí mismo puede ser sujeto indiferente de diversas quiddidades posibles" (193/167). Por lo tanto, la materia delimita, individualiza la quiddidad. Materia est principium individuationis (193/168).

\subsubsection{Concluyendo: el ser humano es "espiritualidad sensible"}

El resultado principal de lo dicho hasta ahora es que "el ser humano es espíritu en tal forma que para llegar a ser se introduce $-y$ se ha introducido ya siempre entitativamente- en la materia y, por tanto, en el mundo" (195/168). Este rasgo no es accesorio de su ser espíritu, sino que es una "determinación intrínseca" (innere Bestimmung) del mismo. El ser humano es "espiritualidad sensible" (sinnliche Geistigkeit) (195/169).

Esto no quiere decir que la espiritualidad, en cuanto facultad especial del ser humano, sea sensible, sino que este, por razón de su espiritualidad receptiva (hinnhemend), "necesita de una facultad sensible" para llegar a "su propio fin, que es la aprehensión del ser en general" (195/169). El ser humano es "espiritualidad sensible" en cuanto "espíritu en la materia”. Y Rahner insiste en el punto: "El alma, siendo espíritu, se introduce de por sí, per se, en la materia" (loc. cit.).

Para entender mejor este aspecto crucial, es necesario precisar la relación aquí establecida entre materia y sensibilidad. Porque aunque Rahner ha puesto énfasis en que debemos entender la primera en su sentido metafísico tomista y no en el sentido del "concepto moderno de materialidad física y química” (187/162), termina asociando el conocimiento receptivo humano -y su naturaleza espiritual misma- con la concreta sensibilidad $^{31}$. A esto se refiere el autor en el capítulo XI de $H W$ sobre la índole histórica del ser humano en cuanto espíritu: si el ser humano es espíritu en la materia (ser material), ahora se agrega que, por ser tal, es "espíritu histórico", es decir, en la historia como ámbito del espacio/

31 Cf. C. Schickendantz, Autotrascendencia radicalizada..., 84-93. 
tiempo. El camino a seguir será el desarrollo de dos notas características de la materia: como principio de espacialidad y como principio de temporalidad.

Primero, la materia como principio de la espacialidad de un ente. La quiddidad nos aparece como lo universal, esto es, como una nota o determinación que puede subsistir muchas veces (puede repetirse) en el "en qué" de la materia. Y la materia es, como se ha dicho, "principio de individuación". Ella hace posible numerar algo que es lo mismo. Como principio de repetición de lo mismo, la materia es el principio del número. Número quiere decir "cantidad". La materia es así principio de cantidad, función que también cumple dentro del ente individual: ella constituye al ente individual como cuantitativo en sí. Ahora bien, si un ente en virtud (Kraft) de su más íntima constitución esencial tiene a la materia como su principio esencial (Wesensprinzip) interno, es un ente espacial (räumlich)" (197/172).

Segundo, la materia como principio de temporalidad. La materia se nos manifiesta como la posibilidad indeterminada de entidad. Por eso, la quiddidad determinada que subsiste en la materia, cuando se trata de un ente material, está siempre en "movimiento", orientada al "futuro" de nuevas posibles determinaciones. En otras palabras, la temporalidad es propia de la materia como potencia. Las nuevas determinaciones posibles de la materia se excluyen en parte, porque la realización de todas ellas no puede darse de una sola vez o simultáneamente. La realización plena de ese conjunto de posibilidades de un ente material solo sería posible en una sucesión. O sea, el ente material es temporal, con una temporalidad que no es simplemente medida extrínseca de la duración de la existencia de un ente, sino su "extenderse intrínsecamente [...] hacia la total realización de sus posibilidades [... y] cada una de ellas, como posibilidad de una materia, es de por sí transitoria y está ordenada dinámicamente a otra, por la cual ella misma es sustituida y suprimida en cuanto tal" (199/173).

Aplicando lo dicho al ser humano: por su esencia está en el espacio y el tiempo. Su quiddidad es la de la materia, por lo que su entidad es reiterable en su identidad específica. En otras palabras: cada ser humano es uno dentro de un género. Por su estructura óntica de ser material, es "repetible" en su quiddidad propia; puede haber muchos seres humanos. Y así como a propósito de la temporalidad de un ente se dijo antes que 
un ente material no puede nunca actualizar totalmente y de una vez toda la amplitud de sus posibilidades, así tampoco un solo individuo humano puede encarnar su quiddidad total y simultáneamente sin referencia a sus semejantes. "El ser humano (Mensch) solo es real en una humanidad (Menschheit)" (201/174).

La espacio-temporalidad pertenece a la constitución esencial del hombre, quien es histórico en el sentido concreto de una historia humana, es decir, en libertad. El ser humano es histórico en cuanto actúa libremente, "incluso y fundamentalmente en su trascendencia hacia Dios y por tanto en la determinación de su posición para con el absoluto" (201/175). Historicidad en libertad implica: carácter único, irrepetibilidad (Einmaligkeit) e incalculabilidad (Unberechenbarkeit) (201/175). La naturaleza también está sometida a cambios, pero historia solo se da donde lo singular irrepetible y el valor intrínseco (Eigenwert) de algo rebasan la modalidad de caso (Fallhaftigkeit) y el valor de posición de ese algo dentro de una serie (Stellenwert).

4.4. El ser humano, espíritu en el mundo, y la historicidad de una posible revelación

Se plantea ahora la pregunta acerca de en qué medida esta historicidad del ser humano determina su apertura al Dios de una posible revelación libre, haciendo de esta apertura una auténtica potentia oboedientialis humana para la revelación. Ha quedado establecido que la historicidad constituye lo propiamente humano de la trascendencia o apertura del espíritu; además, que el ser humano tiene esta apertura al ser en general en la medida en que es conocimiento "receptivo". Este conocimiento es intrínsecamente sensible y, así, "condición necesaria de esa trascendencia hacia el ser en general...” (213/186s). La sensibilidad, por tanto, proviene del espíritu, es una facultad del mismo. El espíritu, para ser tal, se introduce en la materia; en otras palabras: el espíritu se introduce en el mundo para hallarse ante el ser en general. De ahí la tercera tesis de ontología general: "Todo ente puede ser hecho presente en el horizonte del fenómeno mundano, mediante la palabra” (229/199); y la correspondiente tercera tesis de antropología metafísica: "El ser humano es el ente que en su historia debe prestar oído a la revelación histórica de Dios, que posiblemente advendrá en forma de palabra humana" (249/213). 
Si la sensibilidad es una facultad del espíritu, este solo puede tener acceso al ser en general (y al ser absoluto de Dios) si "al introducirse en la materia se hace capaz de contacto con los seres materiales en el espacio y en el tiempo" (215/186). Luego, para el ser humano en cuanto espíritu, el ser solo es luminoso en el encuentro del ente material, es decir: solo se relaciona con el ser mediante el mundo. Y "solo le es posible una salida (Ausgang) hacia Dios en una entrada (Eingang) en el mundo" (215/186). El ser humano no puede realizar el retorno a sí (introversión) que le da acceso al ser y a Dios, sino "saliendo" (extraversión) hacia el mundo (Welt) como ámbito que comparte con otros (Mitwelt) y como entorno o ambiente (Umwelt).

REFLEXIONES FINALES DESDE UNA ANTROPOLOGÍA DEL “ESPÍRITU EN EL MUNDO”

El presente trabajo ha analizado la noción de "espíritu" en el pensamiento de Karl Rahner en un momento decisivo de su itinerario intelectual, esto es, en la transición desde la antropología esbozada en su libro Geist in Welt (1939), en la perspectiva de una metafísica del conocimiento, a una profundización de la misma como establecimiento de las bases de una filosofía de la religión, en Hörer des Wortes. A partir de este fundamento, como sabemos, Karl Rahner se abocaría, por una mezcla de factores biográficos y propiamente intelectuales, a la construcción de una de las obras teológicas más relevantes del siglo XX y hasta ahora.

Estamos en presencia de un pensador cristiano que sigue siendo para la teología y para la Iglesia en general, un modelo de respuesta al desafío de "dar razón de nuestra esperanza" (1Pe 3,15) en el mundo y en la cultura que compartimos con muchos otros. Una buena manera de hacerlo es mostrar, como Rahner, el carácter razonable y significativo de la visión cristiana del ser humano y del mundo, a partir de las categorías de pensamiento filosóficas que se fueron posicionando en las bases de la modernidad. Frente a ellas, y tras siglos de aquella actitud más bien cerrada y apologética que caracterizó a diversas corrientes del pensamiento católico neoescolástico, Rahner representa una nueva propuesta, en la que se combinan, con coraje, la decisión de entablar un diálogo y un rigor intelectual que no es menos crítico que la intrínseca criticidad moderna. No se trataba, para él, de una asunción meramente incondicional o ingenua de los grandes principios de la Aufklärung. En este sentido es posible sopesar la importancia de los pensadores por los que Rahner se 
dejó influir, tanto del ámbito propiamente cristiano y católico -Joseph Maréchal y Pierre Rousselot-, como del ámbito puramente laico de la modernidad ilustrada: Kant, a través de las perspectivas maréchalianas, y Martin Heidegger con su ontología existencial.

Pero, finalmente, lo que le da su sentido más propio al propósito de Rahner, es que todo lo anterior se articula en $G W$ y en $H W$ como un ejercicio de diálogo con la modernidad en el esfuerzo de un redescubrimiento radical de uno de los pensadores más relevantes de la tradición católica: Tomás de Aquino. Se trata de una especie de primicia de la impronta que caracterizaría, algunos decenios más tarde, al Concilio Vaticano II: asumir el desafío de una necesaria "puesta al día" (aggiornamento) de la propia comprensión cristiana del hombre y del mundo, pero no como desde una tabula rasa, sino a través de una estricta "vuelta a las fuentes" (Ressourcement), en busca de la más genuina identidad.

El gran aporte de Karl Rahner tiene que ver, por lo demás, con su metodología. Su camino es, ante todo, el ser humano y, desde el punto de vista disciplinar, el ámbito de la antropología. Lo suyo es un "recentramiento antropológico" del cristianismo, haciéndose así eco del protagonismo del sujeto en el pensar moderno. Es lo que se traducirá en su marechaliana asunción de la perspectiva "trascendental", en el sentido kantiano. Pero, precisamente, he ahí el matiz decisivo: lo antropológico, con dicho "recentramiento", y el reenfoque "trascendental" para la comprensión del ser humano y de todas las grandes dimensiones de su existencia, no se entenderán como un movimiento regresivo a un autocentramiento ciego, sino, por el contrario, como un reconocimiento de lo que en él constituyen las condiciones de posibilidad de una apertura radical al infinito, al ser en general, al ser absoluto. En esta perspectiva, Rahner puede mantenerse, en $H W$, en el plano de la filosofía, pero al mismo tiempo estableciendo las bases de una filosofía de la religión con ribetes de una antropología teológico-fundamental, como intentamos explicarlo.

El propósito principal de este trabajo ha sido ofrecer al lector una ayuda para comprender, mediante una mirada al pensamiento de Karl Rahner en los comienzos de su obra, el sentido y la relevancia de una "nueva" manera de entender la relación entre trascendencia e inmanencia; una manera ciertamente contestataria del extrinsecismo de ciertas corrientes neoescolásticas que marcaron al pensamiento católico hasta la 
primera mitad del siglo XX, y que hoy en día todavía perviven en diversas manifestaciones. Una manera que, por una parte, reivindica a Tomás de Aquino por todo lo que su antropología metafísica puede seguir diciendo hoy al mundo, y que, por otra, hace posible una sana, necesaria y a la vez crítica asunción de perspectivas fundamentales de la cultura moderna. Estas intuiciones de Karl Rahner siguen siendo una contribución a la comprensión cristiana del ser humano como "espíritu", es decir, como alguien que realiza el sentido de su existir en apertura a la trascendencia, pero no en la fuga mundi, sino, por el contrario, mediante un radical enraizamiento en la realidad de la historia, asumiendo los desafíos de este concreto aquí y ahora insoslayable, en el que se prepara y anticipa el sentido definitivo de ese mismo existir. 
